\section{LEARNING AND RETARDATION}

International Review of Research in Mental Retardation, Vol. 2

Edited by Norman R. Ellis. Pp. xiii +366 . (New York: Academic Press, Inc.; London: Academic Press, Inc. (London), Ltd., 1966.) 92s.

Tris is the second volume to be published under the above title, and others are promised. The purpose of the series is to provide a reference source to present research and thinking, and to stimulate further investigations.

No attempt is made to present a complete review of all types of research into all aspects of retardation in each volume, which would be extremely difficult if not impossible. In the present volume emphasis is placed on psychological researches into the mechanisms of learning in retardates. Six of the book's ten sections deal with this subject, and all these originate from centres in the United States, indicating their intense activity in this direction. International flavour is given to the book by the addition of two sections which present a broad review of research in Norway and France respectively. The remaining two sections review studies of the relationship between the autonomic nervous system and behaviour, and psychotherapeutic procedures.

Each section is complete in itself, is well written and documented, and there is little scope for criticism. The book as a whole, however, is fragmentary. The reader who expects to gain a wide perspective of research in mental retardation will be disappointed. It would be helpful for the main emphasis of the volume to be indicated in a sub-title. Psychologists engaged in research on learning in retarded children will wish to have this volume close at hand, but most other workers will prefer to see it on library shelves for their occasional reference and to retain the high price of $92 \mathrm{~s}$. in their own pockets.

K. S. HoLx

\section{CANCER RESEARCH}

\section{The Thymus}

Its Role in Immune Responses, Leukaemia Development and Carcinogenesis. By Donald Metcalf. (Recent Results in Cancer Research, Vol. 5.) Pp. xii +144 . (Berlin and New York : Springer-Verlag, 1966.) 24 D.M. Immunological Aspects of Viral Oncolysis

By Jean Lindenmann and Paul A. Klein. (Recent Results in Cancer Research, Vol. 9.) Pp. viii +86 . (Berlin and New York: Springer-Verlag, 1967.) 18 D.M. ; $\$ 4.50$.

New Trends in the Treatment of Cancer

Edited by L. Manuila, S. Moles and P. Rentchnick. Pp. xiv +206 . (Berlin and New York: Springer-Verlag, 1967.) 32 D.M.

THE above series of reviews is sponsored by the "Swiss League against Cancer", the aim being to present brief summaries of recent developments in cancer research. The monograph on the thymus is a simplified account of the present status of our knowledge concerning this organ. The author is an expert on mouse leukaemia, and was the first to demonstrate the relationship between the thymus and murine leukaemia. The monograph contains much information, partly derived from the author's own experiments, and partly collected from extensive lists of reports. The role of the thymus in the immune response, and the possible mechanism by which control is exercised, is discussed competently and clearly. A stimulating chapter deals with the implication of the thymus in the development of cancer. The arguments marshalled by the author will convince the reader that the thymus, far from being a vestigial organ without function, is involved in the body's defence system against infection and cancer. Animal experiments seem to provide the evidence. This monograph will be valuable help to those who wish to enter into the expanding field of tumour immunology.

The second volume being reviewed deals with viral oncolysis, another topic closely associated with the problem of host-tumour relationship. It centres around the interesting phenomenon of tumour cell destruction by viruses, in which the host defence mechanism has been stimulated indirectly. The authors show that mice, which are genetically resistant to myxoviruses, can be cured of non-specific transplantable tumours by means of tumour-adopted strains of influenza virus. The book has some interesting chapters, in which the authors attempt to answer the question: Why can tumours, which are antigenetically different from their host, grow, and what is the nature of host resistance? It seems that humoral antibodies, which are not directed against known histocompatibility antigens, play a major part in this immune reaction.

The third volume contains reviews, written by experts in tumour chemotherapy, radiotherapy and surgery. These contributions contain, besides many technical details, discussions on general principles. This volume is written for practising physicians, who are the first to be called on to diagnose cancer and to choose the method of treatment. The books are well produced, references well up to date and the illustrations are informative; they will be useful to many workers in the field of cancer.

$$
\text { P. C. Koller }
$$

\section{FISH OF CLAY}

Faune Ichthyologique du London Clay

By Edgard Casier. Appendice: Otolithes des Poissons du London Clay par Frederick Charles Stinton. Pp.xiv +496 . Atlas: 68 plates. (London: British Museum (Natural History), 1966.) 600s. the two volumes.

THE appearance of Casier's long awaited work on the Eocene fishes of the London Clay marks what is probably the end of an era of elassical descriptive palaeoichthyology. By any standards it ranks as a useful addition to the literature, filling as it does a major gap in our knowledge of early Tertiary fish faunas. In addition the volume includes an appendix by Stinton on the otoliths found in the same rocks.

Casier gives descriptions of 124 species belonging to seventy-six genera, of which forty-one species and twentyone genera are new. It is evident that the fauna represented is far more varied than that now found in the Channel and the North Sea. There are thirty-four species of elasmobranch with only a few holocephalans and, in the main, the cartilaginous fishes are similar to contemporary forms, emphasizing that the modern shark faunas were already established by the Eocene. This is in striking contrast to the bony fish. Fifty-two out of fifty-eight genera, based on skulls, are extinct, but only five out of twenty-eight families of teleosts have suffered extinction. A sturgeon is present and three pycnodont species representing the last of this once important holostean group. An A mia-like species also occurs. In the material described by Casier, only five living teleostean genera are represented, suggesting that at this period the evolution of the modern teleosts was at an early stage. Because only five of the twentyeight families listed are extinct, the main lines of the teleost radiation were clearly already established.

From his study, Casier concludes that the majority of the fish were neritic but with a considerable proportion of bathypelagic forms. Most of the London Clay fish were fish-eaters, but about 22 per cent of them fed on shellfish. More than 60 per cent of the fauna was characteristic of tropical and sub-tropical seas, therefore Casier suggests that the small proportion of cold water forms present must 